\title{
O DEBATE EVOLUTIVO É RELEVANTE PARA A LINGUÍSTICA?
}

\section{IS THE EVOLUTIONARY DEBATE RELEVANT FOR LINGUISTICS?}

\author{
Maurício Fernandes Neves Benfatti* \\ pesquisador independente e membro do grupo de pesquisa Linguagem, Cognição e Comunicação - \\ $U F P R / C N P Q$ \\ Elena Godoy ${ }^{* *}$ \\ $U F P R$
}

Resumo: O programa minimalista propõe um modelo de evolução da linguagem e um programa de pesquisas comparativo, interdisciplinar e empírico para a questão. A concepção de que a linguagem é uma capacidade emergente somente na nossa espécie sugere que os processos de seleção e de adaptação não influenciaram decisivamente na emergência de tal característica. Paralelamente, a pragmática cognitiva de orientação relevantista desenvolve, há mais de trinta anos, uma concepção de evolução de comportamento comunicativo que diverge das posturas centrais do programa minimalista. Este trabalho tem o intuito de apontar para questões epistemológicas e metodológicas que decorrem da confrontação entre ambas as propostas. A afirmação principal defendida aqui é a de que a adoção de uma perspectiva fortemente adaptacionista para a comunicação (viés relevantista) e fracamente adaptacionista para a linguagem/recursividade (viés minimalista), considerando a recursividade, assim como a comunicação verbal, capacidades emergentes da cognição humana, é possível desde que a centralidade da sintaxe, defendida pelo modelo gerativista e sutilmente reafirmada no programa minimalista, seja deixada de lado em prol de um modelo que não se furte a apontar uma explicação natural da comunicação via linguagem.

Palavras-Chave: Evolução da linguagem. Evolução da comunicação. Teoria da relevância. Programa minimalista.

\begin{abstract}
The minimalist program proposes a model of language evolution and a comparative, interdisciplinary and empirical research program for the issue. The conception that language is an emerging capacity only in our species suggests that the selection and adaptation processes did not decisively influence the emergence of this characteristic. At the same time, the relevantist-oriented cognitive pragmatics has for more than thirty years developed a conception of the evolution of communicative behavior that diverges from the central postures of the minimalist program. This work aims to highlight epistemological and methodological issues that arise from the confrontation between both proposals. The primary statement defended here is that the adoption of a strongly adaptationist perspective for communication (relevant bias) and weakly adaptationist for language/recursion (minimalist), considering recursion, as well as verbal communication, emerging capacities of human cognition, it is possible since the centrality of the
\end{abstract}

\footnotetext{
* Doutor em Letras/Estudos Linguísticos pela Universidade Federal do Paraná (UFPR). E-mail: mfpandeiro@gmail.com.

** Doutora em Linguística pela Universidade Estadual de Campinas (Unicamp). E-mail: elena.godoi@gmail.com.
} 
syntax, defended by the generative model and subtly reaffirmed in the minimalist program, is left aside in favor of a model that does not shy away from pointing out a natural explanation of communication via language.

Keywords: Evolution of language. Evolution of communication. Relevance theory. Minimalist program.

\section{INTRODUÇÃO}

Dennett (1995) considera que, ao formular a Teoria da Evolução, Darwin teve a melhor ideia que uma mente humana já teve. Embora a afirmação pareça conter uma atitude acrítica acerca da teoria em questão, não é incomum que outros acadêmicos a utilizem para se referir ao potencial explanatório possibilitado pelo desenvolvimento de abordagens evolutivas. Grande parte do fascínio que o evolucionismo exerce na ciência contemporânea se deve ao fato de toda a diversidade de formas de vida existentes na face da Terra poder ser explicada em termos materiais de causa e consequência. Assim, o evolucionismo pode ser concebido como uma abordagem naturalista e materialista para a complexificação de características biológicas formais. No entanto, é válido lembrar que, muito embora a postura evolucionista seja comprometida com a explicação de fenômenos naturais e formais, a metodologia empreendida na observação e descrição dos processos de evolução natural biológica é eminentemente funcionalista, ${ }^{1}$ visto que os processos de regulação da evolução - seleção e adaptação - são demonstrados a partir da ideia de que um novo traço formal (uma característica fenotípica) aleatório, viabilizando uma melhor eficácia na transmissão de informação hereditária de um indivíduo, tende, ao longo de gerações, a se espalhar por toda a população de indivíduos daquela espécie. Assim, uma característica formal que funcione de maneira a facilitar que um indivíduo deixe descendentes será selecionada pelo processo de adaptação biológica.

Segundo Bickerton (2007), apesar do grande avanço da Linguística dentro de seu próprio território disciplinar de atuação, a área de estudos ignorou solenemente o debate sobre a evolução da linguagem. Este autor ainda enfatiza que cada vez mais acadêmicos de outras áreas têm produzido trabalhos relevantes a respeito de tema. No entanto, devido à própria natureza transdisciplinar da discussão, Bickerton (2007) conclama linguistas a ocuparem seus lugares no debate das diversas questões polêmicas suscitadas pelo tema. Ao que parece, este autor ignora o fato de que, ao menos desde a década de 1970, o debate sobre a evolução da linguagem tem sido posto em pauta por pesquisas não comprometidas com uma suposta autonomia da sintaxe.

Neste trabalho, buscaremos evidenciar que boa parte das posturas que ignoram os avanços do debate sobre a evolução da linguagem se deve à rejeição por parte de alguns teóricos de qualquer pesquisa que não se concentre nas propriedades sintático/recursivas da linguagem. Para tanto, argumentaremos que a sensibilidade ao contexto é uma característica que sistematicamente interage com o sistema linguístico, mas que tem sido negligenciada (embora reconhecida) frente à capacidade de processamento linguístico. Tal distorção do objeto de estudos tem favorecido a

\footnotetext{
${ }^{1}$ Um dos principais problemas à época da formulação da Teoria da Evolução das espécies era a ausência de uma explicação formal para os mecanismos de transmissão de características hereditárias. Esta aparente deficiência teórica foi suplantada quase meio século depois da edição de “A origem das espécies” (DARWIN, 1964), com o desenvolvimento da genética. No entanto, ressalte-se aqui que ao longo do século XX ambas as posturas, formais/genéticas e funcionais/evolutivas, complementaram-se e embasaram rotas de mútuo e progressivo desenvolvimento.
} 
descrição da linguagem a despeito de toda e qualquer noção de função adaptativa que tal característica possa vir a exercer em um sistema biológico. Dessa forma, tomam-se como empíricos alguns dados que, por estarem presentes nas línguas naturais, são considerados como presentes na mente de maneira inescrutável, ao passo que se exclui de tal status de descrição qualquer dado tangível pelo escrutínio da linguagem em uso, mas que não se evidencie ao observar a linguagem de maneira isolada.

Para tanto, buscaremos demonstrar que a Teoria da Relevância (TR, daqui por diante) se constitui numa alternativa empiricamente plausível para o estudo da evolução da comunicação humana. Não apenas da comunicação linguística, mas sim de toda e qualquer forma de comunicação ostensiva. A perspectiva relevantista (SPERBER; WILSON, 1986/1995; WILSON; WHARTON, 2006; WILSON; SPERBER, 2004), que surgiu como uma alternativa ao modelo cooperativo de comunicação inferencial proposto por Grice (1975), tomou rumos mais ambiciosos nas últimas duas décadas por promover decididamente uma integração entre perspectivas antropológicas, psicológicas e linguísticas sobre os mecanismos envolvidos na efetivação da comunicação e da cultura humana. Tal transdisciplinaridade explícita promove a descrição da linguagem em um nível artefactual.

Assim, o relevantismo busca lançar luz aos mecanismos mentais que proporcionam comportamentos ostensivos de interação que nos servem como ferramentas de transmissão de pensamentos. Ou seja, a capacidade biológica à significação e à cultura é posta em escrutínio, não centralizando as análises única e exclusivamente na evolução biológica do sistema linguístico. De tal forma, a performance cultural é considerada como fruto de uma competência pragmática. Consideramos que essa metodologia é um passo crucial na diferenciação da TR das abordagens funcionalistas clássicas (pouco comprometidas com o debate evolutivo), visto que o relevantismo embasa sua proposta em um funcionalismo adaptativo no qual, sendo a linguagem um sistema que evoluiu autonomamente ou não, observa-se que a capacidade de inferir e derivar informações relevantes a partir do processamento linguístico não é nem trivial, nem tampouco um processo assistemático. Note-se, portanto, que a comunicação é colocada em escrutínio não a partir do reconhecimento de intenções, mas sim, considerando tal capacidade, geralmente chamada de psicologia de senso comum, como decorrente de uma capacidade geral à inferência. De tal maneira, a função biológica da comunicação humana não residiria na codificação/decodificação de informações (como tradicionalmente a comunicação é descrita), mas na capacidade de inferir informações potencialmente úteis, utilizando evidências oriundas de todos os sistemas cognitivos de interface com os sistemas de processamento estrutural. Como veremos, essa postura é totalmente divergente da concepção de que comunicação linguística, como sistema biológico, é inescrutável. Dessa forma, não se desconfia de que a linguagem tenha um processamento sistemático, autônomo e biologicamente enraizado, porém não se exclui a alternativa de que outros sistemas de mesma natureza exerçam influência decisiva nos resultados eficazes obtidos pela mente ao processar linguagem ou comportamentos de comunicação.

\section{LINGUAGEM: SISTEMA AUTÔNOMO OU COMPLEXO?}

Persistência parece ser ingrediente fundamental para os empreendimentos científicos bem sucedidos. A tese de que os processamentos sintáticos são autônomos e centrais aos 
processamentos linguísticos acompanha Chomsky ao longo de toda a sua carreira acadêmica. Se Chomsky, no apogeu do gerativismo, enfatizando a importância de concentrar esforços científicos na competência linguística, concebia que o desempenho comunicativo é mais um mistério do que um problema científico (CHOMSKY, 1975), atualmente, com o programa minimalista, reafirma essa postura ao sugerir que, apesar de ser a característica distintiva da espécie humana, a linguagem não evoluiu para o uso comunicativo e, portanto, o escrutínio da comunicação verbal não traria conhecimento sistematizável sobre seu objeto (HAUSER; CHOMSKY; FITCH, 2002; FITCH; HAUSER; CHOMSKY, 2005). Visto que não há, nas proposições de tal viés, nenhuma relevância evolutiva sendo apontada para a cultura e toda a gama de manifestações artefactuais humanas, o minimalismo parece sugerir que a diversidade funcional de estruturas culturais não é relevante do ponto de vista evolutivo, e que somente a diversidade formal da linguagem pode vir a ser explicada cientificamente.

A tese de que apenas o mecanismo recursivo de linguagem pode ser descrito como sistema biológico considera que somente os mecanismos de agrupamento e de deslocamentos de estruturas linguísticas possuem sistematicamente um efetivo funcionamento ótimo, deixando, assim, as supostas imperfeições da comunicação linguística na conta da interferência que os sistemas cognitivos em interface com a linguagem exercem nela. Assim, indiretividade, vagueza, ambiguidade e a possibilidade da transmissão de informações errôneas ou falsas são decorrentes do fato de o sistema linguístico operar de acordo com dados oriundos do sistema sensório-motor e "algum tipo de sistema de pensamento (concepção, intenção e assim por diante)” (CHOMSKY, 2006, p. 133). Ao assumir que nenhum dos sistemas cognitivos evoluiu para a comunicação ou para o desempenho linguístico, Chomsky supõe que a grande questão não é se a mente evoluiu para o uso da linguagem, mas sim se a linguagem satisfaz as condições de interface com os outros sistemas com os quais ela opera. E assevera:

Por exemplo, se você tentar desenvolver a teoria de um automóvel que não anda, com um projeto péssimo, que pára de funcionar, o carro que você tinha em Amherst, por exemplo. Se você quisesse desenvolver uma teoria desse carro, você ainda tentaria tornar a teoria tão boa quanto possível. O que quero dizer é que você pode ter um objeto péssimo, porém ainda querer tornar a teoria tão boa quanto possível. (CHOMSKY, 2006, p. 119).

Os preceitos minimalistas parecem apontar para a recursividade sintática como a única coisa que efetivamente é funcional (concebendo tal termo dentro de uma ideia de otimalidade biológica). Por sua vez, Reboul (2017, p. 28) observa que a recursividade é uma habilidade relevante, pois fornece uma possibilidade teórica de produzir sentenças infinitamente longas, não importando se as pessoas de fato produzem essas sentenças ou não. Desse modo, para a autora, a infinidade discreta é uma propriedade estrutural e não comportamental. Sendo assim, da mesma forma que o fígado não evoluiu para que se possa tomar vinho, o órgão da linguagem não evoluiu para que se possa comunicar. O único dado a ser tirado da analogia seria o de que os outputs do fígado são funcionais, da mesma que forma que os outputs do sistema linguístico também o são. Dessa forma, não interessaria notar se linguagem sofre interferência ou interfere nos sistemas com os quais faz interface, mas que o órgão da linguagem recebe inputs funcionais (que possuam condição de input) e processa-os de maneira ótima para que os outros sistemas 
operem. Assim, sintaxe e recursividade não seriam apenas as características centrais na evolução da linguagem, mas a própria essência da evolução da nossa espécie.

No entanto, ao menos desde a década de 1970, os argumentos por uma centralidade da sintaxe recebem críticas acentuadas não apenas pelo seu caráter radical e centralizador de uma contenda dita transdisciplinar, mas principalmente por lançar mão de hipóteses que enfraquecem a descrição de qualquer sistema cognitivo que atue diretamente em interface com o sistema linguístico. Pinker (2008) e Lakoff e Johnson (2002), por exemplo, estão entre os que consideram que a linguagem e os sistemas conceituais se encontram muito atrelados em suas formas ótimas de funcionamento para que tenham evoluído de maneiras desvencilhadas. Se o neocartesianismo chomskiano refuta qualquer explicação que advogue por alguma noção de consciência por trás da manifestação linguística, o interesse de Pinker pelas categorias inatas de Kant sugere que, ao menos parte da explicação do processamento linguístico atribuído por Chomsky à estrutura sintática é, de fato, oriunda da organização inata da mente para lidar com questões conceituais e, portanto, não seria uma questão necessariamente linguística. Assim, a hipótese coevolutiva de Pinker considera que a estrutura argumental evoluiu de forma a tornar o mundo dos conceitos acessível ao sistema linguístico. Tal descrição supõe obviamente intensa atuação em interface entre os sistemas de linguagem e conceituais. Dessa forma, o dualismo chomskiano seria deixado de lado por uma visão holística, na qual ao menos os conceitos aos quais as palavras se ligam não seriam mistérios, mas sim problemas esperando por escrutínio científico adequado.

Argumento semelhante parece ser o de Franchi (1992), que considera o aspecto criativo da linguagem descrito por Chomsky descuidado em relação à centralidade que a linguagem parece exercer na constituição da própria atividade humana. Um dos principais problemas do modelo gerativista, segundo Franchi (1992), é a assunção de que um número finito de categorias fixas e pré-determinadas combinadas reiteradamente seria suficiente para explicar o papel que a linguagem ocupa na própria estruturação da criatividade (não apenas linguística) exibida pela nossa espécie. Assim, Franchi (1992) descreve o modelo de criatividade proposto por Chomsky como um modelo horizontal de criatividade em detrimento de um modelo vertical e constitutivo da linguagem que supõe similaridades entre linguagem e outros sistemas, visto que estruturas linguísticas: "suportam o devaneio sem volta das similitudes e da metáfora, sem quadros fixos de valores, sem limites categoriais precisamente impostos, sem necessidade de conclusões” (FRANCHI, 1992, p. 27).

De forma geral, não é a modularidade da linguagem que se julga impertinente no modelo gerativista/minimalista, mas a centralidade que a descrição dessa estrutura ocupa nesses modelos. Um exemplo disso são os teóricos da chamada Psicologia Evolucionária, que consideram a mente como um conjunto de sistemas cognitivos que foram esculpidos pela evolução biológica de modo que os efeitos da atuação psicológica individual podem ser explicados em termos naturais (TOOBY; COSMIDES, 1992; SAPOLSKY, 2017; MERCIER; SPERBER, 2017; FISKE; TAYLOR, 2017; HEYES, 2018). Um dos questionamentos mais pertinentes desses teóricos reside na postulação tradicional de autores como Chomsky e Fodor (1983) de que a mente deve ser concebida a partir de uma divisão entre processamentos periféricos e centrais. Esse questionamento parece necessário a uma Psicologia Evolucionária, pois seria tal divisão que proporciona uma visão distorcida dos efeitos da atuação cognitiva como defectivos. Isso ocorre 
porque essa postura se choca frontalmente com o preceito básico da perspectiva evolucionária de que a mente é, basicamente, um sistema complexo, constituído de vários sistemas, com a função principal de auxiliar indivíduos em suas tomadas de decisões.

Uma das teses centrais da Psicologia Evolucionária é a de que os circuitos e mecanismos psicológicos de nossa espécie foram selecionados para se ajustarem aos estilos de vida dos nossos ancestrais pré-humanos, habitantes do período Pleistoceno e, consequentemente, não se ajustam necessariamente aos estilos de vida humanos atuais, saturados de hábitos culturais. Aprofundando essa noção dentro de uma Antropologia Cognitiva, Sperber (1996) defende essa postura a partir da distinção de dois conceitos pertinentes a um módulo cognitivo especializado, o domínio específico (proper domain) de computações mentais ao qual um módulo foi selecionado e o domínio real/efetivo (actual domain), no qual esse módulo nos é útil contemporaneamente (SPERBER, 1996, p. 136). Um dos exemplos dados por Sperber diz respeito aos processamentos mentais necessários à locomoção bípede e automotiva. A locomoção bípede humana envolve desafios específicos da postura ereta peculiar de nossa espécie. É, portanto, natural a suposição de que há mecanismos encapsulados e modulares especializados em calcular as informações necessárias para que se ande de maneira eficaz (de forma que o indivíduo não esbarre em obstáculos a toda hora, chegue aos locais que pretende ir etc.). Se tal hipótese é viável, seria razoável esperar que esses mesmos módulos especializados em computar informações necessárias à locomoção bípede também estejam envolvidos na locomoção automotiva, mesmo que o comportamento de locomoção bípede seja formalmente diferenciado do comportamento de locomoção automobilística. Uma questão relevante aqui diz respeito ao comportamento ótimo de andar (que foi desenhado por evolução biológica) em comparação ao comportamento ótimo de dirigir (que envolve demandas totalmente contemporâneas, portanto, culturais).

Assim, para a Psicologia Evolucionária, muitos dos comportamentos que são concebidos como ineficazes podem, na realidade, ser concebidos como uma roupagem contemporânea que o desenvolvimento sócio-histórico de culturas humanas dá aos comportamentos decorrentes dos nossos processos cognitivos inatos, selecionados em uma era geológica em que as culturas humanas inexistiam (KAHNEMAN, 2011; SCOTT TURNER, 2018). Não custa lembrar que, para tal viés, a própria comunicação linguística desempenha um papel crucial na disseminação de informações relevantes ao próprio desenvolvimento de culturas humanas. No entanto, esse papel é comunicativo e não necessariamente estrutural (quer dizer, antes relacionado aos efeitos interativos em indivíduos que possuem linguagem do que a uma eficácia quanto à transmissão de informações). Obviamente, não estamos propondo que a mobilidade permitida por automóveis possui em si defectividade, mas é necessário apontar para o fato de que nossa espécie não está adaptada a muitas das situações nas quais podemos nos ver ao dirigir. Um boi atravessando uma rodovia representa uma séria ameaça à qual seres humanos não poderiam estar adaptados, visto que a velocidade envolvida no ato de dirigir em estradas é substancialmente uma capacidade cultural e contemporânea. O fato de o trânsito automobilístico ser uma causa frequente de mortes de indivíduos sadios é claramente uma evidência de que o comportamento de direção possui características mal-adaptativas. No entanto, se esse comportamento está mesmo enraizado em módulos mentais, não é difícil compreender porque há pessoas que gostam de dirigir em velocidades altíssimas mesmo em situações nas quais não há nenhuma forma de controle dos riscos. De maneira geral, qualquer comportamento específico de locomoção, seja ele bípede ou não, deve gerar benefícios adaptativos. Assim, qualquer incremento mental ao gosto pela velocidade 
(como uma sensação de prazer, por exemplo) pode ajudar a explicar a história evolutiva de uma dada espécie. No entanto, a não ser em casos extremos, locomover-se rapidamente sem o auxílio de máquinas automobilísticas não apresenta sérios riscos à vida. Isso é dramaticamente diferente no caso das velocidades atingidas pelos veículos atuais. Uma refutação óbvia do viés gerativista/minimalista reside na rejeição da assunção de que a mente é dividida em processos periféricos e centrais, dos quais apenas os periféricos estariam ao alcance da ciência moderna. Isso porque muito daquilo que se concebe como efeito de uma atuação obscura de um módulo central pode ser concebido à luz de interações entre módulos especializados a lidar não apenas com informações oriundas do mundo físico, mas também com informações de base conceitual e atributiva. Essa postura concebe que um funcionalismo para a mente é plausível, desde que comprometido com o escrutínio dos mecanismos mentais envolvidos na efetivação dos comportamentos culturais, deixando assim de lado o empirismo puro, que supõe o comportamento cultural efetivo como objeto de estudos.

Vale notar, como pondera Castilho (2007), que uma abordagem meramente funcionalista para a linguagem está fadada ao insucesso se ela não estiver comprometida com uma visão de linguagem que a situe como um objeto dinâmico e complexo. Quer dizer, Castilho (2007) parece apontar para a observação de que um funcionalismo linguístico é possível desde que concentrado em processos que, em interface, possibilitam a emergência de um significado linguístico. Essa postura está em consonância com a maioria das críticas levantadas até aqui sobre a centralidade da sintaxe, inclusive aquela que leva a inferir que a autonomia modular da linguagem obrigatoriamente implica a centralidade da sintaxe. Como veremos, o viés relevantista é uma alternativa para a cognição comunicativa que reserva uma descrição modular e autônoma para a linguagem, mas não considera plausível que os processamentos sintático/recursivos sejam centrais nem no que tange à comunicação linguística efetiva, nem no que tange à evolução da linguagem. Assim, complexidade não demandaria assistematicidade e tampouco a diversidade funcional cultural estaria à margem da discussão, ou ainda pior, seria fruto de uma mente infinitamente plástica e moldável (como gostariam os que negam a modularidade da mente).

Esses exemplos são suficientes para nos fazer supor que tanto os mecanismos mentais de conceituação e de inferências devem fornecer não apenas condições de input para os outputs do processamento linguístico, mas o próprio processamento linguístico demanda intensa atuação dos demais sistemas para que um indivíduo possa avaliar uma estrutura como linguisticamente bem estruturada ou não. De tal forma, a hipótese de uma coevolução entre os sistemas cognitivos em interface com o sistema linguístico nos parece bastante convincente. Primeiro porque releva a importância da compreensão transdisciplinar do objeto linguagem, e, principalmente, porque parece ser corroborada por inúmeras fontes de críticas válidas e pertinentes ao modelo minimalista. O principal compromisso para uma agenda séria de investigações científicas é o de desvencilhar a noção de que a descrição de linguagem como objeto complexo e dinâmico implica a não aceitação de uma especialização modular para a linguagem. Assim, pode ser mantido o status tão apreciado de observação empírica em linguística, visto que o sistema possui uma autonomia, porém não se exclui que comunicação, conceito e atribuição sejam fenômenos também a serem explicados, visto que o sistema sintático/recursivo não é considerado como central. 


\section{EXAPTAÇÃO, CULTURA E LINGUAGEM}

Gould e Vrba (1982) buscaram em Nietzsche (1887/1998) o termo exaptação para descreverem um poderoso conceito em ciência evolutiva: o de que há mecanismos biológicos que foram selecionados por causa de uma função para a qual não tinham sido desenhados evolutivamente até então. Um caso clássico seria o dos ossos responsáveis por nossa audição, que teriam sido desenhados evolutivamente por fornecerem melhor articulação à mandíbula de nossos ancestrais, mas que, por fornecerem benefícios individuais favorecendo a audição, acabaram sendo selecionados para outros fins, que não os de sustentação da mandíbula. Dessa forma, a bigorna, o martelo e o estribo teriam chegado à sua conformação formal atual devido a um processo de seleção que agiu sobre outro processo de seleção previamente em decorrência.

É comum assumir como exaptação qualquer forma de cultura humana. A escrita, por exemplo, seria um comportamento para o qual não fomos adaptados, mas somos capazes de utilizar uma série de capacidades biológicas para concretizarmos tal ação. Um dos problemas da concepção de cultura como exaptação reside no fato de se excluir a possibilidade de que seres humanos sejam adaptados a desenvolver culturas diversificadas não apenas quanto à forma, mas também quanto à função. Ou seja, ignora-se que, talvez, sejamos adaptados a exaptar. Pensemos, por exemplo, na agricultura, característica à qual evidentemente não estamos adaptados. Teria a nossa espécie alcançado o enorme sucesso de distribuição ecológica atual sem que tivéssemos empreendido coletivamente e sucessivamente uma história cultural do cultivo de alimentos?

Notoriamente, a abordagem minimalista conclama por uma concepção exaptativa para a comunicação linguística. Visto que os efeitos acarretados por tal tipo de comunicação não seriam decorrentes da evolução da nossa espécie, mas sim de um acaso relacionado à emergência da linguagem em nossa espécie. Talvez aí resida o calcanhar de Aquiles da teorização minimalista. Em primeiro lugar, seria necessária uma argumentação mais convincente a respeito de a linguagem, estruturalmente complexa como é (mesmo deixando de lado as interfaces com os demais sistemas cognitivos), ter emergido em nossa espécie sem uma base formal menos complexa. Seria como se uma célula procarionte tivesse emergido sem a ancestralidade de uma célula eucarionte. Além do mais, uma exaptação é um acaso biológico apenas na origem dos processos ontogênicos (de diferenciação biológica entre indivíduos portadores de tal característica e os não portadores), visto que, a partir do momento em que uma característica exaptada é selecionada, é provável que, geração após geração, ela passe por processos de otimização até a estabilização da função ótima de tal característica ao longo de uma população de indivíduos. Então, mesmo que a linguagem, em seus primeiros estágios ótimos de seleção adaptativa, tenha sido um caso único na natureza de emergência casual de uma estrutura biológica complexa, ainda assim, estaria fadada a depender dos efeitos e funções proporcionáveis a algum indivíduo que a possuísse. Resta perguntar, a quem a linguagem teria sido útil, mesmo que internamente ao próprio sistema mental, se ela não fosse tomada para organizar conceitos e formular inferências?

A concepção de que a capacidade à cultura é modeladora de comportamentos culturais que são adaptativos não por seus resultados a priori, mas sim pelas possibilidades que se abrem, tanto remete à hipótese da inteligência cultural (HERRMANN et al., 2019, TOMASELLO) quanto à hipótese de que a nossa espécie tem uma característica adaptativa intimamente relacionada ao uso massivo que fazemos de representações (SPERBER, 2000). Segundo a primeira hipótese, chimpanzés têm habilidades cognitivas muito parecidas com as nossas para lidar com estruturas 
do mundo físico, porém, a nossa espécie se diferenciaria dos demais grupos de grandes símios porque manifesta, desde muito cedo, habilidades cognitivas mais sofisticadas para lidar com questões sociais. Assim, ao contrário dos primatas, somos cooperativamente altruístas. Ou seja, desde a mais tenra idade, entendemos e aprendemos a usar os gestos/sinais ostensivos, que têm o significado de oferecer algo para o outro, chamar a atenção do outro a favor deste outro, enquanto os primatas entendem e usam apenas os gestos/sinais, que significam a oferta/ favor para eu (TOMASELLO, 2010).

Já a segunda hipótese sugere que a intensa atividade cultural humana é decorrente de nossa sofisticação em usar metarrepresentações (representações acerca de representações). Dessa forma, um estímulo ostensivo (produzido para chamar a atenção de um interlocutor) se diferenciaria de outros estímulos potencialmente significativos.

Para ilustrar o papel da comunicação ostensiva, pondere um quadro, no qual o mesmo tipo de estrutura sonora possa acarretar diferentes redes de relações causais representativas em diferentes contextos, partindo de um contexto não intencional e passando por contextos mais ou menos ostensivos. Suponha que Daniel está andando na rua e escuta algum desconhecido tossindo. Ele pode utilizar o seu próprio conhecimento intuitivo sobre resfriados para inferir que o desconhecido está resfriado. Agora suponha que Daniel está assistindo TV na sala com Ana, sua namorada, e que ambos saibam que ela está resfriada e que há caixas de lenços de papel na despensa. Ana pode simplesmente deixar a caixa de papel utilizada e vazia ao alcance dos olhos de Daniel e esperar que ele, ao ouvi-la tossindo, seja capaz de inferir que seria elegante que ele fosse até a despensa buscar mais uma caixa de lenços. Ou ela poderia ostensivamente emular os sons de uma tosse acentuando a tonalidade e intensidade e ostensivamente apontar para a caixa de lenços vazia enquanto faz cara de quem merece uns mimos de vez em quando. Como fica evidente, o caráter ostensivo da comunicação humana demanda grande sensibilidade aos contextos não só de quem busca tornar pública uma intenção comunicativa, o alvo da comunicação também atua correlacionando as evidências públicas (as estruturas de comunicação) às informações contextuais que lhes são acessíveis (informações mentais previamente processadas e potencialmente relevantes). Assim, a significação natural pode ser descrita como sendo aquela que Daniel pode ter ao ouvir o som de uma tosse, e demanda apenas uma representação interna análoga relacionando espirros e tosse a resfriados. No entanto, no caso em que Ana ostensivamente se comporta de modo a suscitar um significado específico em Daniel, tem-se um caso de significação não-natural, no qual a experiência análoga não é suficientemente concisa para se chegar a conclusões adequadas. Tal demanda por inferências demarca o campo do significado não-natural.

Ambas as concepções acima expostas remetem ao debate iniciado por Premack e Woodruff (1978) sobre se a capacidade de teorizar acerca da mente alheia é uma capacidade distintiva humana. Para os autores, este questionamento é válido visto que, em muitos aspectos, chimpanzés parecem também possuir essa capacidade. Call e Tomasello (2008), em recente revisão dos trabalhos desenvolvidos posteriormente ao questionamento de Premack e Woodruff (1978), sugerem que a aparente inabilidade de chimpanzés em lidar com falsas crenças demarca a especificidade da complexidade do uso dessa capacidade em humanos. Para Call e Tomasello (2008), essas limitações observáveis em chimpanzés (que, embora reconheçam intenções alheias, não reconhecem quando outros indivíduos possuem crenças sobre o mundo que não 
coincidem com a realidade) são demonstrativas de que, em um sentido amplo: por mais que chimpanzés possuam algum tipo de teoria da mente, essa consideração deve vir acompanhada da observação de que os graus de complexidade dessa característica são muito menos salientes em chimpanzés do que na nossa espécie.

Nesse sentido, a atividade simbólica e cultural humana parece ser inerentemente uma questão de lidar não apenas com estruturas, visto que seres humanos são intuitivamente capazes de conceber que o comportamento alheio é orientado pelas representações mentais que os indivíduos possuem, mesmo quando tais representações são crenças falsas. Como argumenta Sperber (2000), prever o comportamento alheio eficazmente é uma vantagem adaptativa considerável, o que parece indicar a existência de dispositivos biológicos não apenas para a linguagem, como sugerido por Chomsky, mas também para mecanismos cognitivos especializados em formular hipóteses metarrepresentativas plausíveis.

É a partir de tal consideração que acreditamos que uma abordagem correlacional para a significação depende da compreensão dos mecanismos cognitivos envolvidos na derivação individual de informações potencialmente relevantes. O que está em questão é a visão muito difundida de que é necessário assumir que há algo socialmente tácito acerca do significado de estruturas comunicativas para que se possa colocá-las em escrutínio científico. Esse recorte metodológico exclui a consideração pertinente dos verdadeiros fenômenos a serem explicados. Ou, como questionam Sperber e Wilson (1995, p. 36): “Qual é a lógica por trás do princípio e das máximas cooperativas?”’ Afinal, assumindo o significado como tácito e socialmente convencionado, do ponto de vista biológico, ainda falta uma explicação sobre como indivíduos conseguem abstrair o que é convencional, tácito e socialmente difundido. Isso é obviamente necessário para que um indivíduo utilize um significado, seja vinculando-o a uma estrutura, seja interpretando um comportamento ostensivo.

\section{RELEVANTISMO: COMUNICAÇÃO VERBAL COMO SISTEMA OSTENSIVO-INFERENCIAL}

A TR foi originalmente planejada como uma reformulação do modelo inferencial de comunicação, proposto inicialmente por Grice (1957) como um esforço concentrado nas inferências, sendo que, posteriormente, este esforço foi deslocado para a descrição da cooperação comunicativa (GRICE, 1975). Se, para a filosofia da conversação griceana, a significação é uma questão de cooperação entre as partes interlocutoras, para a TR, a significação é uma questão de derivação individual de informações. Ou seja, para o relevantismo, a significação comunicativa não reside simplesmente na atribuição intencional do falante, visto que é o ouvinte que significará a evidência linguisticamente codificada de um querer dizer. Há uma rejeição, portanto, da ideia de que conhecimento compartilhado seja um fenômeno natural, mas sim, uma abstração distorcida da natureza do objeto. Segundo Sperber e Wilson (1995, p. 38): “[...] mutual knowledge is a philosopher's construct with no close counterpart in reality”. Isso porque a base sobre a qual o conhecimento individual se efetiva está atrelada à eficiência individual quanto à percepção e às capacidades inferenciais. Os autores explicam que os motivos que produzem

\footnotetext{
2 "What is the rationale behind the co-operative principle and maxims?” Todas as traduções apresentadas no corpo do texto são nossas.
} 
a constituição dos ambientes cognitivos, nos quais representações internas são geradas, serão inevitavelmente diversos de pessoa a pessoa da seguinte forma:

Todos os humanos vivem no mesmo mundo físico. Todos nós estamos envolvidos na empreitada de uma vida em derivar informações desse ambiente comum e de construir a melhor representação mental possível. Nem todos construímos a mesma representação, devido às diferenças em nossos ambientes físicos mais estreitos, por um lado, e em nossas habilidades cognitivas, por outro. As habilidades perceptivas variam em eficácia de um indivíduo para outro. As habilidades inferenciais também variam, e não apenas em eficácia. As pessoas falam línguas diferentes, elas dominam conceitos diferentes; como resultado, elas podem construir representações diferentes e fazer inferências diferentes. Elas também têm memórias diferentes, diferentes teorias que trazem à experiência de diferentes maneiras. Portanto, mesmo que todos compartilhassem o mesmo ambiente físico restrito, o que propomos chamar de ambiente cognitivo ainda seria diferente (Id.; Ibid.). ${ }^{3}$

Desta forma, comunicação humana é descrita como situada no meio de um continuum entre a significação natural e a não-natural. Ou seja, o código utilizado para ostensivamente chamar a atenção de um interlocutor é concebido apenas como uma evidência do significado comunicativo, o que implica que o significado linguístico seria apenas parte da evidência do real significado intencionado pelo falante. Caberia ao ouvinte formular uma hipótese comunicativa plausível tanto no momento de solucionar as vaguezas e indiretividades típicas de enunciados, quanto no momento de atribuir uma intencionalidade plausível à proposição. Para tanto, em tal abordagem, a linguagem é concebida como ferramenta mental de organização estrutural. Dessa maneira, o significado linguístico não seria um atributo da linguagem, mas sim, da comunicação verbal. Neste ponto é possível apontar uma concordância entre o relevantismo e o minimalismo - o fato de a linguagem não ser concebida biologicamente como instrumento de comunicação. Porém, a reação frente a tal constatação é totalmente diferente. O minimalismo julga que a comunicação linguística é a evidência empírica de que a única espécie que apresenta linguagem é a nossa, no entanto, não concebe que a comunicação tenha qualquer relevância para a evolução da linguagem. Tal postura é aparentemente ambígua, visto que, se de fato a linguagem não é uma ferramenta interativa, mas sim de organização estrutural, não é tão segura assim a afirmação de que nenhuma outra espécie possua uma base inata de organização estrutural. Afinal, a diferença pode residir exatamente no fato de outras espécies não se utilizarem da linguagem como formas de comunicação (como no caso do uso de línguas naturais).

Outro ponto a se notar é que, apesar de a linguística tradicionalmente descrever a linguagem a partir da noção de uma dupla-articulação, a não concepção de um papel comunicativo biológico para a linguagem deveria presumir que a articulação significativa não é sistematicamente

\footnotetext{
3 "All humans live in the same physical world. We are all engaged in a lifetime's enterprise of deriving information from this common environment and constructing the best possible mental representation of it. We do not all construct the same representation, because of differences in our narrower physical environments on the one hand, and in our cognitive abilities on the other. Perceptual abilities vary in effectiveness from one individual to another. Inferential abilities also vary, and not just in effectiveness. People speak different languages, they have mastered different concepts; as a result, they can construct different representations and make different inferences. They have different memories, too, different theories that they bring to bear on their experience in different ways. Hence, even if they all shared the same narrow physical environment, what we propose to call their cognitive environments would still differ".
} 
ligada à articulação estrutural, mas que tal somente ocorre no caso das línguas naturais humanas. Neste sentido, o foco do debate recai sobre a comunicação, porém, não sobre a assunção de que a linguagem evoluiu para a comunicação, mas sim concebendo que as línguas naturais oferecem uma ótima brecha de observação indireta dos mecanismos envolvidos na derivação dos significados comunicativos. Segundo os autores:

As atividades que envolvem necessariamente o uso de uma língua (isto é, um sistema representacional governado por gramática) não são comunicativas, mas cognitivas. A linguagem é uma ferramenta essencial para o processamento e a memorização de informações. Como tal, deve existir não apenas em humanos, mas também em uma grande variedade de animais e máquinas com capacidade de processamento de informações. Qualquer organismo ou dispositivo com uma memória deve ser capaz de representar estados passados do mundo ou de si mesmo. Qualquer organismo ou dispositivo com a capacidade de extrair inferências deve ter um sistema representacional cujas fórmulas tenham relações sintáticas e semânticas entre si. Claramente, essas habilidades não se limitam aos seres humanos. O grande debate sobre se os seres humanos são as únicas espécies a ter linguagem baseia-se em um equívoco sobre a natureza da linguagem. $\mathrm{O}$ debate não é realmente sobre se outras espécies, além dos humanos, têm idiomas, mas se eles têm idiomas que eles usam como meio de comunicação ${ }^{4}$ (SPERBER; WILSON, 1995, p. 173).

Agora é possível explicar duas coisas na noção relevantista de comunicação: a ideia de que a linguagem é produto de estruturas de organização interna e a de que línguas naturais são fenômenos comunicativos que agregam representações oriundas de outros sistemas mentais. O fato de a TR considerar as representações semânticas como ferramentas da comunicação ostensiva-inferencial pressupõe que a comunicação verbal só poderia ter algum benefício adaptativo em um quadro evolutivo, no qual ostensão e inferência fossem anteriores à comunicação verbal. Nesse sentido, não apenas a linguagem é adaptativa, mas as línguas naturais também o são, mas, no caso, por uma funcionalidade biológica comunicativa. A saber, para a TR, a comunicação verbal é um caso paradigmático de comunicação ostensiva, visto que a utilização de linguagem para a estruturação de informações comunicativas ostensivas é de longe, mesmo com toda a indiretividade e vagueza que lhe é peculiar, o comportamento mais eficaz no que diz respeito à evidenciação de uma intenção comunicativa. Em outras palavras, é menos custoso cognitivamente a um falante expor um pensamento publicamente por meio da comunicação verbal do que por meio dos demais tipos de comportamentos ostensivos. Basta lembrar de um grupo de amigos jogando Imagem e Ação para entender o que tal tipo de concepção supõe. A mímica é um meio efetivo de comunicação, porém, as condições estruturais de limitar a

\footnotetext{
4 "The activities which necessarily involve the use of a language (i.e. a grammar-governed representational system) are not communicative but cognitive. Language is an essential tool for the processing and memorizing of information. As such, it must exist not only in humans but also in a wide variety of animals and machines with information-processing abilities. Any organism or device with a memory must be able to represent past states of the world or of itself. Any organism or device with the ability to draw inferences must have a representational system whose formulas stand in both syntactic and semantic relations to each other. Clearly, these abilities are not confined to humans.

The great debate about whether humans are the only species to have language is based on a misconception of the nature of language. The debate is not really about whether other species than humans have languages, but about whether they have languages which they use as mediums of communication".
} 
significação não-natural por meio de gestos parecem muito mais reduzidas do que no caso do uso da linguagem. Ainda assim, um enunciado sempre oferece uma gama de significados que lhe são possíveis de serem atribuídos. Dessa forma, centrando a atenção na psicologia do interlocutor que busca significar um comportamento comunicativo, Sperber e Wilson julgam que a comunicação deve ser descrita em termos de maximização das expectativas de relevância, ou seja, partindo da ideia de que a mente, como sistema complexo e dinâmico que é, busca derivar o máximo possível de informações relevantes, otimizando os custos de processamento cognitivo. Vale lembrar que teoricamente esta não é uma atitude consciente, ou seja, descrever os aparatos da razão não demanda conceber que o raciocínio é conscientemente buscado pelos indivíduos. Um interlocutor não escolhe a hora de gastar ou não energia para tentar pinçar uma hipótese plausível para um comportamento comunicativo. Ele simplesmente procura por significado até encontrar um que lhe satisfaça, ou a própria mente acaba deixando de lado esta tarefa até que, por acaso, ela possa vir a se completar. Como no caso em que não se compreende uma piada: ou abre-se a brecha de se perguntar aos interlocutores próximos o significado da piada (e arcar com todas as consequências sociais disso), ou simplesmente a tarefa é deixada de lado sem que conscientemente se faça tal decisão.

\section{ROTAS DE APROXIMAÇÃO TEÓRICA}

Um ponto comum óbvio rumo a uma aproximação teórica entre o minimalismo e o relevantismo é o de que, a princípio, para os dois modelos, a mente funciona computando dados. Em certa medida, a própria pragmática relevantista tem como base a concepção de buscar uma alternativa computacional para a geração e para a interpretação de significados. Não por acaso, Sperber e Wilson (1995; SPERBER, 1994) defendem modelos massivamente modulares não apenas para a comunicação verbal, mas para a própria atuação significativa por trás das culturas humanas. Talvez seja notável que o interesse principal de Sperber (1985) em naturalizar a comunicação resida na possibilidade de naturalizar a própria antropologia, área à qual ele é originariamente filiado. E, obviamente, tal proposta passa pela naturalização dos processos centrais da psicologia da razão.

Como o relevantismo não desconsidera a afirmação de que o papel biológico da linguagem é antes interno ao sistema do que exterior a ele, é natural esperar que a especificidade da linguagem humana possua forte correlação com outras funções do pensamento humano em si. Na realidade, uma visão fortemente adaptacionista para a comunicação inferencial passa pela assunção de que módulos conceituais e atributivos também possuem a forma lógica da linguagem, mas que operam com funções específicas de enriquecimento pragmático ao longo do processamento da comunicação verbal. Dessa forma, é desnecessário assumir um atomismo significativo, sugerido pelas restrições de condições de input do produto do processamento linguístico ao sistema central de processamento. Conforme tal proposta, módulos estruturais, conceituais e inferenciais atuam de maneira interdependente. Imaginado um cenário inicial de aquisição de significados, os outputs dos módulos estruturais seriam correlacionados em módulos conceituais por meio de mecanismos lógico-causais (por meio de mecanismos chamados pela Lógica Formal como modus ponens e modus tollens). No processo específico de aquisição de linguagem, um recém-nascido não observaria apenas os sons das línguas naturais, mas sim, correlacionaria todos os estímulos potencialmente significativos do momento da enunciação. 
Os outputs de um processo como tal ainda seriam conceitos vagos, visto que ainda não haveria sido carregada nenhuma informação de fundo psicológico acerca do enunciador. Esses estímulos vagos passariam pelos processos de inferência significativa e voltariam a estar disponíveis aos outros sistemas mentais. Dessa forma, ao reconhecer padrões comunicativos previamente processados, o sistema conceitual já possuiria representações enriquecidas pragmaticamente acerca do padrão, tornando ainda mais eficiente os sucessivos processamentos conceituais e inferenciais.

A importância de um tal modelo para a comunicação supõe que a mente possui uma característica heurística, visto que faz apostas acerca dos significados ao longo dos processos de conceituação e inferência. Nesse sentido, a noção de cancelabilidade dos cálculos pragmáticos parece promissora, dado que, ao longo da vida, um indivíduo tende a modular seus conceitos e significados de acordo com os efeitos contextuais que tais representações podem vir a desempenhar. Não é incomum, por exemplo, relatos de pessoas que se tornam ateístas depois de vivenciarem a perda de um familiar de um modo muito cruel, incompatível com uma suposta benevolência divina. Pode-se adotar uma explicação pragmática para tal cancelamento de uma determinada rede de relações causais associáveis logicamente e responsáveis pelo conceito de um criador divino e benevolente. Na realidade, o próprio processo de aquisição lexical parece ser intrinsecamente heurístico e cancelável na medida em que um conceito lexical se mostra não totalmente eficiente a um usuário de uma língua. Quer dizer, aparentemente adota-se uma rede de explicações para determinados conceitos lexicalizáveis até que se tenha uma evidência de que partes de nossa explicação significativa sobre aquele conceito eram errôneas ou insuficientes. Basta lembrar que palavras como relevância, recursão, linguagem ou comunicação podem suscitar reformulações intensas a um estudante de linguística ao longo de sua vida. Nesse sentido, é necessário que fique explícito que relevância é uma noção comparativa e explanatória. Comparativa no sentido de que se pode imaginar o mesmo estímulo sendo interpretado em momentos diferentes. Quanto maiores forem os efeitos contextuais positivos acarretados por este estímulo em um indivíduo, maior será relevância relativa de tal estímulo para esse indivíduo. E explicativa porque não possui ambições analíticas ou pedagógicas (com coisas como "aprenda a ser relevante em seu trabalho”, “o significado por trás das canções de Tom Jobim” etc.), mas sim, descritivas (no caso, da própria atividade inferencial, tida como gatilho da variação funcional da cultura humana).

Este modelo mental supõe que a principal distinção da comunicação humana para a comunicação não-humana reside na complexa capacidade a metarrepresentações que nossa espécie possui. A comunicação verbal possui exemplos dos diferentes níveis de metarrepresentatividade que devem existir na natureza, incluindo as que somente humanos são capazes de articular. Um enunciado é em si uma metarrepresentação, ou seja, uma representação pública de uma representação mental. Mas nem todas as sentenças possuem em si algum nível explícito de metarrepresentação, isto é, algum conteúdo proposiconal acerca de algum conteúdo proposicional. Vejamos os exemplos:

(1) Volto logo.

(2) Ana acha que eu volto logo.

(3) O Paulo me disse que a Ana acha que eu volto logo.

(4) Vou embora porque o Paulo me disse que a Ana acha que eu volto logo. 
Em (1), embora exista uma informação linguisticamente estruturada, a proposição é praticamente vazia a respeito de conteúdo representativo, afinal, o que (1) pode representar do mundo? Já em (2), temos, de fato, uma metarrepresentação, ou seja, uma proposição tangível que pode representar algo do mundo. Para o relevantismo, não é negável que ambas estas formas de metarrepresentações existam na natureza de maneira mais ou menos frequente. Porém, conteúdos proposicionais como em (3) e (4), que demandam a correlação entre a representação do falante acerca da representação de Paulo sobre a representação de Ana, seriam casos só encontráveis em seres humanos. Como essas relações metarrepresentativas são ilimitadas linguisticamente, não há por que supor que tais relações também não estejam presentes no próprio sistema mental de maneira ilimitada.

Um caminho de interdisciplinaridade entre minimalistas e relevantistas poderia residir na investigação da relação entre metarrepresentação e recursividade embarcada, que aparenta ser uma propriedade específica da linguagem humana, característica estrutural que nos permite construir sentenças como:

(5) O Paulo, que é amigo da Júlia, que é primo da Ana, me disse que a Ana acha que eu volto logo.

Colocado desta forma, uma concordância entre minimalistas e relevantistas de que linguagem é antes um sistema de organização estrutural do que comunicativo, mas que a comunicação verbal abre brechas, por suas especificidades funcionais, ao escrutínio dos processos conceituais e inferenciais e leva a indicar uma aproximação não só possível, mas também frutífera. Essa rota parece corroborável também por expectativas não lexicalistas para a sintaxe, que buscam reduzir a atuação sintática a traços menores da linguagem, como a morfologia (HARLEY; NOYER, 1999) e traços elementares (STARKE, 2011), e entregam a maior parte do papel de lexicalização a processos pós-sintáticos. Vale lembrar que o reconhecimento/atribuição de informação lexical ocorre de maneira rápida ao longo de processos de interação verbal. Isso sugere mecanismos conceituais e inferenciais tão encapsulados e biologicamente enraizados: tais como um módulo linguístico é tradicionalmente descrito. No entanto, não se espere que tal empreendimento conciliador possa ser forjado de maneira suave. Muitos são os debates que deverão decorrer a partir de uma real confrontação entre essas duas posturas teóricas. No entanto, não deixaria de ser um passo eficaz rumo a uma transdisciplinaridade efetiva em um campo tão marcado pela pluralidade teórica como a linguística contemporânea.

\section{ALGUMAS CONSIDERAÇÕES}

Uma maneira objetiva de responder à pergunta do título deste texto seria a de que sim, o debate evolutivo é relevante aos estudos linguísticos. Mesmo tendo em vista uma visão na qual se busca desvencilhar a descrição da linguagem como um objeto de estudos minimamente afetado pela evolução (porém, ainda assim com um funcionamento ótimo no que concerne unicamente a seu próprio domínio biológico de funcionamento), é possível notar não só que o debate minimalista busca se vincular a uma teorização formal plausível evolutivamente, mas também que tal proposição trouxe um debate novo e promissor à área de estudos. Como salienta Campos (2011, p. 16): 
Seja como for, merece um comentário o fato de que a Linguística Evolucionária, expressão sintética da interdisciplinaridade, passa pela justificativa de que tal debate parece abrir caminho para uma futura e frutífera área de pesquisa.

Se a naturalização da linguística começou a se tornar possível por meio de um conceito biológico para a linguagem tal como proposto pelo gerativismo, um debate necessário para tal finalidade não pode escapar ao crivo do evolucionismo. Para uma postura completamente evolucionista, não é possível deixar despercebida qualquer noção de função que a linguagem em uso possa ter. A comunicação verbal demanda uma explicação de função biológica para além da de estruturação interna. Dessa forma, não só linguagem merece o status de objeto científico, mas a capacidade à geração infinita de significados também é pertinente. A TR, com todos os problemas evidentes de tal propósito acadêmico, parece ser uma rota plausível para a explicação natural da diversidade significativa observável nas línguas naturais. Talvez, o principal entrave para o relevantismo se articular como uma postura séria acerca da linguagem em uso seja a concepção errônea, porém amplamente difundida, de que toda Pragmática deve supor que a linguagem funciona para a comunicação. Mantendo a linguagem em seu status interno ao sistema mental é possível assumir que a comunicação inferencial apresenta regularidades sistemáticas e é também um fenômeno a ser explicado dentro das boas tradições materiais da ciência contemporânea. Dessa forma, o que se põe em escrutínio é o que o fenômeno linguístico propicia: um caso paradigmático de comunicação ostensiva-inferencial, no qual uma espécie é capaz de utilizar um mecanismo interno para tornar mais relevantes as suas manifestações externas de interação e interlocução. Em outras palavras, de certa forma, o objeto de uma Pragmática relevantista não é propriamente a compreensão da linguagem, embora a TR não deixe de ter a perspectiva linguística chomskiana no sentido fraco (em comparação com o chomskianismo forte de sua primeira versão de 1985). A comunicação ostensiva-inferencial, da qual a linguagem é um caso especial, é que passa a ser o foco da atenção teórica.

\section{AGRADECIMENTOS}

Os autores são especialmente gratos aos pareceristas pela leitura atenta do texto original e interlocução estabelecida.

\section{REFERÊNCIAS}

BICKERTON, D. Language evolution: a brief guide for linguists. Lingua, v. 117, n. 3, 2007. p. 510-526. Disponível em: http://www.ucd.ie/artspgs/langevo/langevobriefly.pdf. Acesso em: 5 fev. 2019.

CALL, J.; TOMASELLO, M. Does the chimpanzee have a theory of mind? 30 years later. Trends in Cognitive Science, 12, 2008. p. 187-192. Disponível em: http://email.eva.mpg. de/ tomas/pdf/TICS30.pdf. Acesso em: 20 dez. 2019.

CAMPOS, J.C. Chomsky vs Pinker: nainterface entre Linguística ePsicologia Evolucionária. Letras de Hoje, Porto Alegre, v. 46, n. 3, p. 12-17, jul./set. 2011. Disponível em: http://revistaseletronicas. pucrs.br/ojs/index.php/fale/article/viewFile/9739/6666. Acesso em: 10 fev. 2020. 
CASTILHO, A. T. Abordagem da língua como um sistema complexo: contribuições para uma nova Linguística Histórica. In: CASTILHO, A. T. et al. (Org.). Descrição, História e Aquisição do Português Brasileiro. 1. ed. v. 1, Campinas: Pontes - Fapesp, 2007, p. 329-360.

DARWIN, C. On the origin of species: A facsimile of the first edition. Harvard University Press, 1964.

DENNETT, D. C. Darwin's dangerous idea: evolution and the meaning of life. New York: Simon \& Schuster, 1995.

FISKE, S. T.; TAYLOR, S. E. Social Cognition: From Brains to Culture. SAGE, 2017.

FITCH, W. T.; HAUSER, M. D.; CHOMSKY, N. The evolution of the language faculty: Clarifications and implications. Cognition, v. 97, n. 2, p. 179-210, 2005.

FODOR, J. The Modularity of Mind: an essay on faculty psychology. Cambridge, Massachusets: The MIT Press, 1983.

FRANCHI, C. Linguagem - atividade constitutiva. Cadernos de Estudos Lingüísticos, n. 22, Campinas, 1992. p. 9-39.

GRICE, H. P. Meaning. The Philosophical Review. 66, 1957. p. 377-388.

GRICE, H. P. Logic and conversation. In: COLE, P.; MORGAN, J. (Ed.) Syntax and Semantics, v. 3. New York: Academic Press, 1975. p. 41-58.

HARLEY, H.; NOYER, R. Distributed Morphology. Glot International, v. 4, n. 4, abr., 1999. HAUSER, M. D.; CHOMSKY, N.; FITCH, W. Tecumseh. The faculty of language: what is it, who has it, and how did it evolve? Science, v. 298, n. 5598, p. 1569-1579, 2002a.

HERRMANN, E.; et al. The structure of individual differences in the cognitive abilities of children and chimpanzees. Psychological Science, 21, 2010. p. 102-110. Disponível em: http://www.sciencemag.org/content/317/5843/1360.full. Acesso em: 20 out. 2019.

HEYES, C. Cognitive Gadgets. Harward University Press, 2018.

JAY GOULD, S.; VRBA, E. S. Exaptation; a missing term in the science of form. Paleobiology, v. 8, 1982. p. 4-15.

KAHNEMAN, D. Thinking, Fast and Slow. London: Penguin Books, 2011.

LAKOFF, G.; JOHNSON, M. Metáforas da vida cotidiana. Tradução de M. S. Zanotto e V. Maluf. São Paulo: EDUC, 2002.

MERCIER, H.; SPERBER, D. The Enigma of Reason. Harvard University Press: Cambridge, Massachusets, 2017.

NIETZSCHE, F. W. A genealogia da moral. Tradução de Paulo C. de Souza. São Paulo: Companhia das Letras, 1887/1998.

PINKER, S. Do que é feito o pensamento: a língua como janela para a natureza humana. São Paulo: Companhia das Letras, 2008. 
PREMACK, D.; WOODRUFF, G. Does the chimpanzee have a theory of mind? Behavioural and Brain Sciences, 4, 1978. p. 515-26.

REBOUL, A. Cognition and communication in the Evolution of language. Oxford University Press, 2017.

SAPOLSKY, R. M. Behave: The Biology of Humans at Our Best and Worst. Penguin Press, 2017.

SCOTT TURnER, J. Purpose and Desire. Harper Collins Publishers, 2018.

SPERBER, D. Anthropology and Psychology: Towards an Epidemiology of Representations. In: Man, New Series, v. 20, n. 1, 1985. p. 73-89. Disponível em: http://www.jstor.org/ stable/2802222. Acessado em: 27 jun. 2020.

SPERBER, D. Metarepresentations in an Evolutionary Perspective. In: SPERBER, D. (Ed.) Metarepresentations: A Multidisciplinary Perspective. New York: Oxford University Press, 2000. p. 117-137.

SPERBER, D. The modularity of thought and the epidemiology of representations. In: HIRSCHFELD, L. A.; GELMAN, S. A. (Ed.) Mapping the Mind: Domain specificity in cognition and culture, New York: Cambridge University Press, 1994. p. 39-67.

SPERBER, D. Explaining Culture: A naturalistic approach. Oxford: Blackwell, 1996.

SPERBER, D.; WILSON, D. Relevance: Communication and cognition. Oxford: Blackwell, 1986/1995.

STARKE, M. Towards elegant parameters: Language variation reduces to the size of lexically stored trees, MS. Barcelona, Spain, 2011. Disponível em: http://ling.auf.net/lingBuzz/001183. Acesso em: 5 jan. 2020.

TOMASELLO, M. Origins of Human Communication. Cambridge, Massachusets: MIT Press, 2010.

TOMASELLO, M.; HERRMANN, E. Ape and human cognition: What's the difference? Current Directions in Psychological Research, 19(1), 2010. Disponível em: http://email. eva.mpg.de/ tomas/pdf/Tomasello_Herrmann_2010.pdf. Acesso em: 10 jan. 2020.

TOOBY, J.; COSMIDES, L. The psychological foundations of culture. In: BARKOW; J.; COSMIDES, L.; TOOBY, J. (Ed.), The adapted mind: Evolutionary psychology and the generation of culture. New York: Oxford University Press, 1992.

WILSON, D.; SPERBER, D. Relevance Theory. In: HORN, L. R.; WARD, G. (Ed.) The Handbook of Pragmatics. Oxford: Blackwell, 2004. p. 607-632

WILSON, D.; WHARTON, T. Relevance and prosody. Journal of Pragmatics, 38, 2006. p. 1559-1579.

Recebido em: jul. 2020.

Aceito em: nov. 2020. 